\title{
Optimization of Mechanical Design Parameters for Missile Foldable Wing Mechanism by Using Design of Experiment Method
}

\author{
Zafer Külünk and Murat Şahin
}

\begin{abstract}
Foldable mechanisms provide many advantages to the aero vehicles. Especially, low storage volume of the vehicles is the main advantage to use these mechanisms while the vehicle is out of flight. In-flight situation, these mechanisms must also be activated and deployed. Deployment in a right time, from the folded to deployed position, is critical for flight health of these vehicles. Therefore, engineers make analysis and several tests on prototypes to optimize the deployment time and to design a valid mechanism. In this study, a missile foldable wing mechanism is examined, working principles and key components of the mechanism for deployment process are explained, and optimization studies on mechanical parameters of these components are completed by Design of Experiment (DOE) method. As a result of this study; parameters of the mechanism components affecting deployment time are determined and a novel foldable missile wing mechanism are designed.
\end{abstract}

Index Terms-Mechanism, aerospace, optimization, design.

\section{INTRODUCTION}

Minimizing the storage space of missiles is an important requirement in aerospace; therefore, foldable wing structures are effectively used in aero vehicles. In order to attain this storage goal; mechanical solutions, which keep the wings in folded position and lock them at desired deployed position after missile is launched, must be designed. These mechanisms include mechanical components like a torsion spring in order to store sufficient energy at folded positon for deployment of the wings. They also include a locking pin that keeps the wing fixed in flight condition [1], [2]. When the missile is inside the launch tube before in-flight scenario, the wings are located in folded position, which keeps them laying on the missile surface. This position maintains the minimum storage space for the missile. Once the missile is fired and leaves the launch tube, the mechanism is activated and the wings are deployed. On the other hand, it is very important for the wings to be deployed in right time after the missile is fired and leave the launching tube.

In this paper; a foldable and deployable missile fixed wing mechanism, which occupies minimum storage space, with a special rotation axis and locking mechanism is analyzed. Parametric analysis of the key components on the deployment time is done. Optimization of these components and determination of the parameters are completed. Finally, efficient foldable missile wing mechanism is designed.

Manuscript received August 1, 2018; revised April 12, 2019.

Zafer Külünk is with Roketsan Missiles Industry, Ankara, Turkey (email: zkulunk@roketsan.com.tr).

Murat Şahin is with the Control Systems Design Department, Ankara, Turkey

\section{Theory ANd Working PrinciPle Of The System}

In literature, different topologies have been proposed for foldable and deployable wing mechanisms. Design ways of these topologies are categorized into several concepts; such as, flexible versus rigid or root deployment versus span extenders [3]. In this study; a novel foldable and deployable rigid wing mechanism is introduced and analyzed. This mechanism is illustrated in Fig. 1-a, which shows both the folded and deployed configurations on the missile coordinate system. From the folded position to the deployed position, the wing rotates around an axis. This axis has a special orientation with respect to the missile coordinate frame, as illustrated in Fig. 1-b; thus, it lets the mechanism deploy from folded position in one degree of freedom [4], [5].

Design of both the deployment and locking mechanisms using the same axis for their operations is the most important aspect of the wing mechanism. This mechanism consists of several mechanical components listed in Table I. These components are labeled with numbers in Fig. 2 which shows the section view of the mechanism in both compact (a) and expanded (b) configurations.

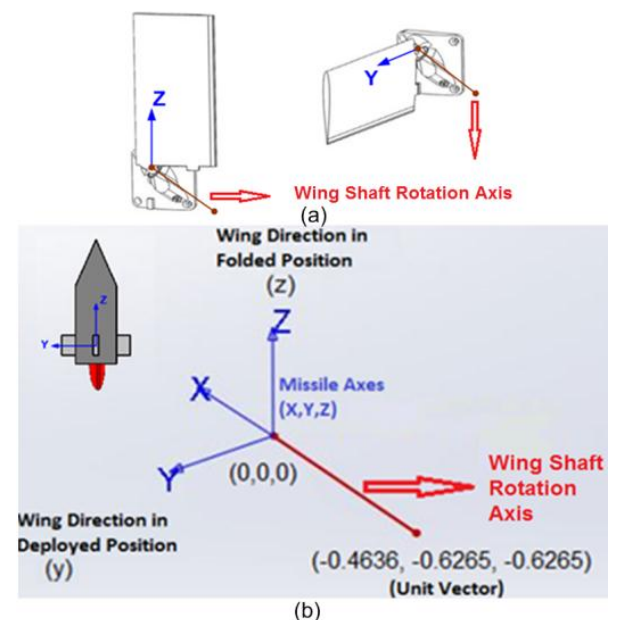

Fig. 1. Folded and deployed positions of the missile wing from left to right (a), orientation of wing shaft axis on missile coordinate system (b)
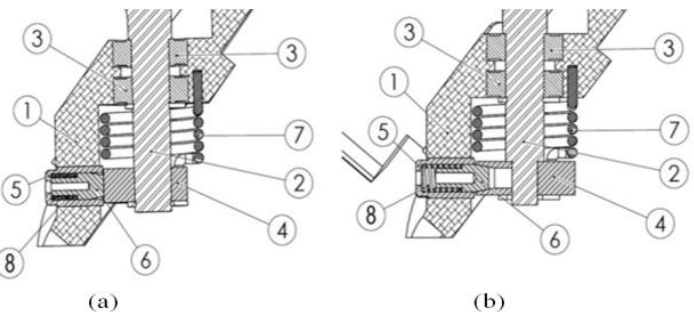

(b)

Fig. 2. Cross sectional view of the mechanism and components orientation (a) folded position of the mechanism, (b) deployed position of the mechanism. 
TABLE I: COMPONENTS OF THE MECHANISM

\begin{tabular}{|c|c|}
\hline Number & Component Name \\
\hline 1 & Main Casing \\
\hline 2 & Wing Shaft \\
\hline 3 & Bearings \\
\hline 4 & Locking Casing \\
\hline 5 & Locking Bushing \\
\hline 6 & Locking Pin \\
\hline 7 & Torsion Spring \\
\hline 8 & Compression Spring \\
\hline
\end{tabular}

Before proceeding to technical design details of the mechanism, brief information about the mission of the components will be given. The first component, named main casing 1) holds the all mechanism together. Wing shaft 2) extends from the wing surface with special angular orientation as shown by Fig. 1-a. Bearings 3) locate the wing shaft inside the main casing 1) accurately and carry aerodynamic load on the wings. The wing shaft 2) is connected to a pre-loaded torsion spring 7) through a part called locking casing 4). Thus, these three parts rotate simultaneously once the missile leaves the launch tube. With this rotational movement, the wing is deployed to its expanded position. When the wing comes to its desired deployed position, compression spring 8) activates the pin 6) which locks the whole mechanism by penetrating into a slot on the cylindrical surface of the locking casing 4). The pin works inside locking bushing 5) which is fixed to the main casing 1).

We would like to note that compression and torsion springs are of utmost importance since stored energy (SE) in them is a key factor on deployment time of the mechanism. The deployment time is related to arrival time of the wing from folded to deployed position as well as the timing of the locking process. Arrival time of the wing is determined by the torsion spring, whereas duration of locking process is determined by the compression spring. They can be minimized by maximizing the SE in springs. On the other hand, safety of those components is also important for reliability of the whole mechanism. In the next sections, we formulate a multi-objective optimization problem in the DOE frame to trade-off those conflicting objectives.

\section{PARAMETRIC ANALYSIS OF THE SPRING ELEMENTS}

As mentioned previous section; key components of the wing mechanism determining the total deployment time are compression and torsion springs. In this section; analyses on the design parameters of those components will be carried out with respect to SE, and engineering constraints for the mechanism will be determined.

The main parameters for the spring design are Elasticity Modulus $(E)$ and Shear Modulus $(G)$. These are determined by spring material. For this study, high carbon spring wire has been chosen as spring material and this material has $\mathrm{E}$ around 203.4E9 $\mathrm{Pa}$ and $\mathrm{G}$ around 83.7E9 $\mathrm{Pa}$ [6]. In addition; wire diameter $(d)$, mean coiling diameter $(D m)$ and coiling number $(N)$ are other parameters which should be determined truly for efficient spring design [7], [8]. Design of these parameters defines the SE level as well as the total deployment time of the mechanism.

Energies of the torsion and compression springs are directly related to spring rate. It means that the higher the rate is, the more energy the spring stores under specific deflection or twisting angle. Stored energies for compression $\left(S E_{x}\right)$ and torsion $\left(S E_{\theta}\right)$ springs can be calculated by the formulas (1) and (2) below [9].

$$
\begin{aligned}
& S E_{x}=\left(R_{x} x^{2}\right) / 2 \\
& S E_{\theta}=\left(R_{\theta} \theta^{2} \pi / 180\right) / 2
\end{aligned}
$$

In the formulas (1) and (2); $R_{x}$ is the compression spring rate, unit of $N / m$ and $R_{\theta}$ is the torsion spring rate, unit of $N \mathrm{~m} / \mathrm{deg}$. Also, $x(m)$ and $\theta$ (deg.) are deflection distance and deflection angle for compression and torsion springs, respectively. The deflection $x$ of the compression spring is difference between spring free length and spring length at folded position. The spring length at folded position is $4.1 \mathrm{~mm}$ for our design. Furthermore; the deflection $\theta$ value of the torsion spring is sum of rotation angle from folded to deployed position and preload applied to torsion spring at deployed position. The mechanism rotation angle from folded to deployed position is around 130 degree.

The spring rates for both compression and torsion springs can be calculated in the formulas (3) and (4), which are presented below [7], [10].

$$
\begin{aligned}
& R_{x}=\left(d^{4} G\right) /\left(8 D^{3} N\right) \\
& R_{\theta}=\left(d^{4} E\right) /(3888 D N)
\end{aligned}
$$

By adding the formulas (3) and (4) into the formulas (1) and (2); we obtain the SE formulas (5) and (6) of the compression spring $\left(S E_{x}\right)$ and the torsion spring $\left(S E_{\theta}\right)$ related to spring parameters.

$$
\begin{aligned}
& S E_{x}=\left(d^{4} G x^{2}\right) /\left(16 D^{3} N\right) \\
& S E_{\theta}=\left(d^{4} E \theta^{2} \pi / 180\right) /(7776 D N)
\end{aligned}
$$

Maximizing the formulas 5) and 6) is main duty to acquire the shortest deployment time of the foldable wing. It can be verified from the formulas 5) and 6) that 4th magnitude of $\mathrm{d}$ is directly proportional to $S E$; but, $N$ and $D$ are indirectly proportional to it. On the other hand; it is expected that single-handed maximizing $S E$ does not give true result; because, mechanical design is a process which has many interactive phases and there are some constraints which restrict this approach. In this study, these constraints can be listed as geometric and reliability of the design.

Maximum allowable design space and manufacturability lead to geometric constraints of spring design, which identify minimum and maximum values of dimensions. Also, the mechanism must endure physical flight conditions. It must perform its task and be safe in flight conditions. Table II and III show the geometric and safety constraints of the springs.

TABLE II: CONSTRAINTS OF THE TORSION SPRING DESIGN

\begin{tabular}{|c|c|c|c|}
\hline Constraints & Min. Value & Max. Value & Type \\
\hline Wire diameter $(\mathrm{d})$ & $1 \mathrm{~mm}$ & $1.7 \mathrm{~mm}$ & Geometric \\
\hline Coiling diameter $(\mathrm{Dm})$ & $15 \mathrm{~mm}$ & $21 \mathrm{~mm}$ & Geometric \\
\hline Coiling Number $(\mathrm{N})$ & 3 & 7 & Geometric \\
\hline Deflection $(\theta)$ & $130 \mathrm{deg}$. & $170 \mathrm{deg}$. & Geometric \\
\hline Safe Angle(SA) & must be bigger than $\theta$ & Safety \\
\hline
\end{tabular}


TABLE III: CONSTRAINTS OF THE COMPRESSION SPRING DESIGN

\begin{tabular}{|c|c|c|c|}
\hline Constraints & Min. Value & Max. Value & Type \\
\hline Wire diameter $(d)$ & $0.3 \mathrm{~mm}$ & $0.5 \mathrm{~mm}$ & Geometric \\
\hline Coiling diameter $(D m)$ & $3.1 \mathrm{~mm}$ & $3.6 \mathrm{~mm}$ & Geometric \\
\hline Coiling Number $(N)$ & 8 & 12 & Geometric \\
\hline Deflection $(x)$ & $6 \mathrm{~mm}$ & $9 \mathrm{~mm}$ & Geometric \\
\hline Factor of Safety $[10]$ & 1.2 & - & Safety \\
\hline
\end{tabular}

\section{OPTIMIZATION OF THE SPRING PARAMETERS}

Many process development and manufacturing applications include large number of input parameters (factors). Process characterization is used to minimize the number of factors by identifying effects of these factors on product quality (response). Complexity of optimization problem results in development of design optimization tools. One effective tool to solve these problems is the DOE method which uses the statistical methods to detect the relationships between factors and responses. This method provides optimal solutions related to the control design experiments created from a design space which is defined by engineers [11]-[13]. Other basic purposes of this cause-andeffect method are minimizing the number of test errors, finding and optimizing a few key arguments that affect the most dependent variables, effective use of resources by finding the necessary and unnecessary inputs, obtaining maximum information with minimum resources, and designing for manufacturability.

For both compression and torsion springs; two-level full factorial design method (TFFD) is applied to observe the effects of factors on SE and safety, also to reach optimum spring design. TFFD examined each factors at two boundary levels (maximum and minimum levels) and observe the effects of factors and their combinations between these levels. In this study, the number of factors in both experiments is 4 . For compression spring, these factors are $d$, Dm, $\mathrm{N}$ and $\mathrm{x}$ (see Table III); for torsion spring, these are $\mathrm{d}$, Dm, $\mathrm{N}$ and $\theta$ (see Table II).

\begin{tabular}{|r|r|r|r|r|r|}
\hline d & Dm & N & Theta & SE & Safe Angle \\
\hline 1,0 & 15 & 3 & 130 & 0,17137 & 130 \\
\hline 1,7 & 15 & 3 & 130 & 1,43127 & 66 \\
\hline 1,0 & 21 & 3 & 130 & 0,12240 & 165 \\
\hline 1,7 & 21 & 3 & 130 & 1,02234 & 96 \\
\hline 1,0 & 15 & 7 & 130 & 0,07344 & 302 \\
\hline 1,7 & 15 & 7 & 130 & 0,61340 & 153 \\
\hline 1,0 & 21 & 7 & 130 & 0,05246 & 453 \\
\hline 1,7 & 21 & 7 & 130 & 0,43814 & 223 \\
\hline 1,0 & 15 & 3 & 170 & 0,29305 & 130 \\
\hline 1,7 & 15 & 3 & 170 & 2,44756 & 66 \\
\hline 1,0 & 21 & 3 & 170 & 0,20932 & 165 \\
\hline 1,7 & 21 & 3 & 170 & 1,74826 & 96 \\
\hline 1,0 & 15 & 7 & 170 & 0,12559 & 302 \\
\hline 1,7 & 15 & 7 & 170 & 1,04895 & 153 \\
\hline 1,0 & 21 & 7 & 170 & 0,08971 & 453 \\
\hline 1,7 & 21 & 7 & 170 & 0,74925 & 223 \\
\hline & & & & & \\
\hline
\end{tabular}

Fig. 3. Factors and responses for torsion spring DOE design.

Fig. 3 shows that 16 experiments are performed to analyze the relationship between factors and responses for DOE analysis of torsion spring. According to DOE results, coefficients and effects of factors on torsion spring SE are shown in Table IV and in Fig. 4, respectively. It is seen on this figure that the most effective factor on SE of torsion spring is combination of wire diameter and deflection (AD).
Second effective one is sole deflection factor (D). However, sole effect of wire diameter (A) is not as much as AD and D.

TABLE IV: CONSTRAINTS OF THE COMPRESSION SPRING DESIGN

\begin{tabular}{|c|c|c|c|}
\hline Factors & $\begin{array}{c}\text { Factor } \\
\text { Symbols }\end{array}$ & $\begin{array}{c}\text { Coefficients } \\
\text { Values }\end{array}$ & $\begin{array}{c}\text { Coefficient } \\
\text { Symbols }\end{array}$ \\
\hline Constant & $f 1$ & $-0,04701$ & $\mathrm{c} 1$ \\
\hline$d$ & $f 2$ & $-2,78138$ & $\mathrm{c} 2$ \\
\hline$D m$ & $f 3$ & 0,13838 & $\mathrm{c} 3$ \\
\hline$N$ & $f 4$ & 0,49817 & $\mathrm{c} 4$ \\
\hline$\theta$ & $f 5$ & $-0,03427$ & $\mathrm{c} 5$ \\
\hline$d \cdot \theta$ & $f 6$ & 0,05729 & $\mathrm{c} 6$ \\
\hline$D m \cdot N$ & $f 7$ & $-0,04034$ & $\mathrm{c} 7$ \\
\hline$d \cdot D m \cdot N$ & $f 8$ & 0,01490 & $\mathrm{c} 8$ \\
\hline$d \cdot D m \cdot \theta$ & $f 9$ & $-0,00105$ & $\mathrm{c} 9$ \\
\hline$d \cdot N \cdot \theta$ & $f 10$ & $-0,00377$ & $\mathrm{c} 10$ \\
\hline$D m \cdot N \cdot \theta$ & $f 11$ & 0,00018 & $\mathrm{c} 11$ \\
\hline
\end{tabular}

In accordance with coefficients in Table IV, experimental $S E$ formula (7) can be derived as shown below.

$$
S E(m J)=1000 .(f 1 . c 1+f 2 . c 2+\ldots+f 11 . c 11)
$$

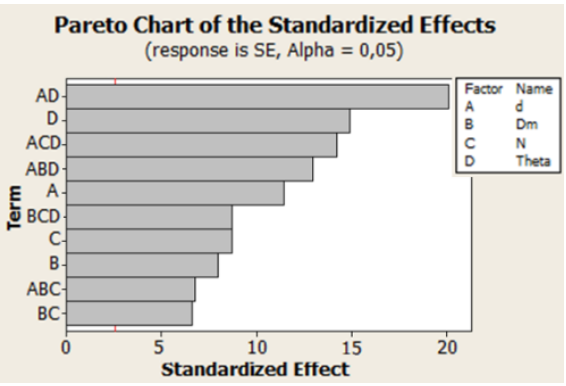

Fig. 4. Effects of factors on stored energy of torsion spring.

Similarly, effects and coefficients of factors for torsion spring SA are also derived. Below, these coefficients and effects on the response are shown in Table $\mathrm{V}$ and in Fig. 5, respectively. From the figure; it can be concluded that the most significant effect on $S A$ is wire diameter factor $(A)$. In addition, the experimental $S A$ formula (8) is derived by coefficients in Table V.

TABLE V: COEFFICIENTS OF FACTORS FOR TORSION SPRING SAFE ANGLE

\begin{tabular}{|c|c|c|c|}
\hline Factors & $\begin{array}{c}\text { Factor } \\
\text { Symbols }\end{array}$ & $\begin{array}{c}\text { Coefficients } \\
\text { Values }\end{array}$ & $\begin{array}{c}\text { Coefficient } \\
\text { Symbols }\end{array}$ \\
\hline Constant & $\mathrm{f} 12$ & 317,071 & $\mathrm{c} 12$ \\
\hline $\mathrm{d}$ & $\mathrm{f} 13$ & $-186,071$ & $\mathrm{c} 13$ \\
\hline $\mathrm{Dm}$ & $\mathrm{f} 14$ & $-21,0476$ & $\mathrm{c} 14$ \\
\hline $\mathrm{N}$ & $\mathrm{f} 15$ & -67 & $\mathrm{c} 15$ \\
\hline Dm.d & $\mathrm{f} 16$ & 12,381 & $\mathrm{c} 16$ \\
\hline $\mathrm{d} . \mathrm{N}$ & $\mathrm{f} 17$ & 37,5 & $\mathrm{c} 17$ \\
\hline Dm.N & $\mathrm{f} 18$ & 9,35714 & $\mathrm{c} 18$ \\
\hline Dm.d.N & $\mathrm{f} 19$ & $-4,52381$ & $\mathrm{c} 19$ \\
\hline
\end{tabular}

$$
S A(\text { Degree })=f 12 . c 12+f 13 . c 13+\ldots+f 19 . c 19
$$

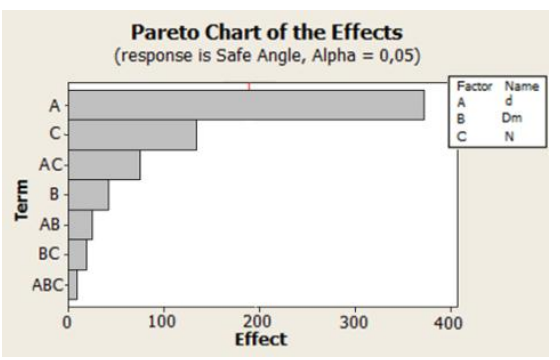

Fig. 5. Effects of factors on safe angle of torsion spring. 
As a result of DOE studies for torsion spring, we tune the spring parameters between maximum and minimum values due to get the highest possible SE and SA for the torsion spring. Therefore, optimum values of the spring parameters are determined, as shown in Table VI. By these values, experimental SE and SA are found as $1103 \mathbf{~ m J}$ and $168.4^{\circ}$, respectively. In addition to the tuning study mentioned above, manufacturability of the torsion spring is also taken into consideration, so reasonable values for these parameters are chosen with this conscious.

TABLE VI: PARAMETERS OF THE TORSION SPRING

\begin{tabular}{|c|c|c|}
\hline Torsion Spring Constraints & Value & Constraint Type \\
\hline Elasticity Modulus (E) & $203.4 \mathrm{E} 9 \mathrm{~Pa}$ & Fixed \\
\hline Wire diameter (d) & $1.6 \mathrm{~mm}$ & Geometric \\
\hline Coiling diameter (D) & $18 \mathrm{~mm}$ & Geometric \\
\hline Coiling Number $(\mathrm{N})$ & 5,5 & Geometric \\
\hline Deflection Angle $(\theta)$ & $160^{\circ}$ & Geometric \\
\hline
\end{tabular}

Same DOE studies are also done for compression spring due to get optimum spring parameters. Fig. 6 shows the factors and responses at boundary levels for this spring. After the DOE analysis is completed, coefficients and effects of factors are achieved for $S E$, as shown in Table VII and Fig.7. Then, experimental $S E$ formula (9) is obtained by these coefficients. It can be inferred from the Fig. 7 that binary and triple combinations of wire diameter factor $(A)$, coiling diameter factor $(B)$ and deflection factor $(D)$ have more significant effect on safe angle than sole ones.

\begin{tabular}{|c|c|c|c|c|c|}
\hline d & Dm & $\mathbf{N}$ & $x$ & SE & Safety \\
\hline 0,3 & 3,1 & 8 & 6 & 0,006401 & 1,40 \\
\hline 0,5 & 3,1 & 8 & 6 & 0,049387 & 0,84 \\
\hline 0,3 & 3,6 & 8 & 6 & 0,004087 & 1,93 \\
\hline 0,5 & 3,6 & 8 & 6 & 0,031535 & 1,17 \\
\hline 0,3 & 3,1 & 12 & 6 & 0,004267 & 2,48 \\
\hline 0,5 & 3,1 & 12 & 6 & 0,032925 & 1,26 \\
\hline 0,3 & 3,6 & 12 & 6 & 0,002725 & 3,41 \\
\hline 0,5 & 3,6 & 12 & 6 & 0,021023 & 1,75 \\
\hline 0,3 & 3,1 & 8 & 9 & 0,014401 & 0,99 \\
\hline 0,5 & 3,1 & 8 & 9 & 0,111121 & 0,56 \\
\hline 0,3 & 3,6 & 8 & 9 & 0,009196 & 1,36 \\
\hline 0,5 & 3,6 & 8 & 9 & 0,070953 & 0,79 \\
\hline 0,3 & 3,1 & 12 & 9 & 0,009601 & 1,77 \\
\hline 0,5 & 3,1 & 12 & 9 & 0,074081 & 0,84 \\
\hline 0,3 & 3,6 & 12 & 9 & 0,006130 & 2,28 \\
\hline 0,5 & 3,6 & 12 & 9 & 0,047302 & 1,17 \\
\hline
\end{tabular}

Fig. 6. Factors and responses for compression spring DOE design

TABLE VIII: COEFFICIENTS OF FACTORS FOR COMPRESSION SPRING SE

\begin{tabular}{|c|c|c|c|}
\hline Factors & $\begin{array}{c}\text { Factor } \\
\text { Symbols }\end{array}$ & $\begin{array}{c}\text { Coefficients } \\
\text { Values }\end{array}$ & $\begin{array}{c}\text { Coefficient } \\
\text { Symbols }\end{array}$ \\
\hline Constant & f20 & 0,0021 & c20 \\
\hline d & f21 & $-0,4508$ & c21 \\
\hline Dm & f22 & 0,0362 & c22 \\
\hline N & f23 & 0,0244 & c23 \\
\hline x & f24 & $-0,0668$ & c24 \\
\hline d.N & f25 & $-0,0448$ & c25 \\
\hline d.x & f26 & 0,308 & c26 \\
\hline Dm.N & f27 & $-0,0092$ & c27 \\
\hline Dm.X & f28 & 0,0099 & c28 \\
\hline d.Dm.N & f29 & 0,0202 & c29 \\
\hline d.Dm.x & f30 & $-0,055$ & c30 \\
\hline d.N.x & f31 & $-0,0063$ & c31 \\
\hline Dm.N.x & f32 & 0,0005 & c32 \\
\hline
\end{tabular}

$$
S E(m J)=1000 .(f 20 . c 20+f 21 . c 21+\ldots+f 32 . c 32)
$$

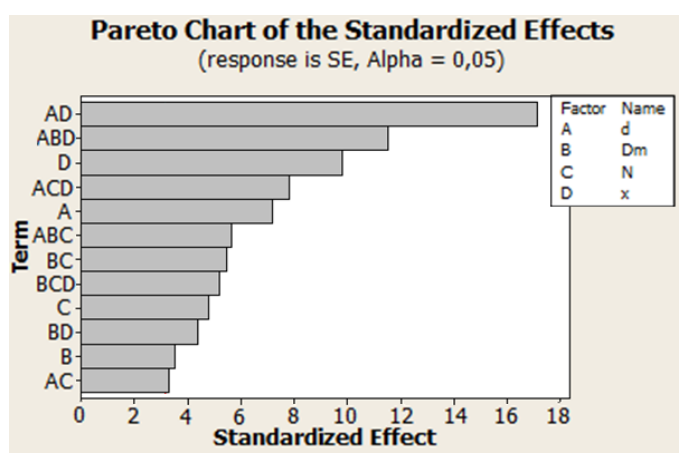

Fig. 7. Effects of factors on stored energy of compression spring.

DOE study results for the compression spring safety are also presented in Table VIII and Fig. 8. This table shows the coefficients of factors on compression spring safety. From these coefficients, experimental safety formula (10) for compression spring is also calculated. Fig. 8 explains the effects of factors on safety of this spring. According to this figure, minimum effect on safety of compression spring comes from coiling diameter factor (B). However; when this factor (B) combines with coiling number factor (C), this combination (BC) becomes the most effective combination on the safety of the compression spring. Therefore; if we want to increase the safety, it is better option to tune coiling diameter and coiling number together instead of coiling diameter alone.

TABLE IX: COEFFICIENTS OF FACTORS FOR COMPRESSION SPRING SAFETY

\begin{tabular}{|c|c|c|c|}
\hline Factors & $\begin{array}{c}\text { Factor } \\
\text { Symbols }\end{array}$ & $\begin{array}{c}\text { Coefficients } \\
\text { Values }\end{array}$ & $\begin{array}{c}\text { Coefficient } \\
\text { Symbols }\end{array}$ \\
\hline Constant & $\mathrm{f} 33$ & $-1,1933$ & $\mathrm{c} 33$ \\
\hline $\mathrm{d}$ & $\mathrm{f} 34$ & 8,3688 & $\mathrm{c} 34$ \\
\hline $\mathrm{Dm}$ & $\mathrm{f} 35$ & $-0,9308$ & $\mathrm{c} 35$ \\
\hline $\mathrm{N}$ & $\mathrm{f} 36$ & $-0,4938$ & $\mathrm{c} 36$ \\
\hline $\mathrm{x}$ & $\mathrm{f} 37$ & 0,3471 & $\mathrm{c} 37$ \\
\hline $\mathrm{d} . \mathrm{x}$ & $\mathrm{f} 38$ & $-1,6242$ & $\mathrm{c} 38$ \\
\hline Dm.N & $\mathrm{f} 39$ & 0,46 & $\mathrm{c} 39$ \\
\hline $\mathrm{d} . D m \cdot N$ & $\mathrm{f} 40$ & $-0,4931$ & $\mathrm{c} 40$ \\
\hline $\mathrm{d} . \mathrm{Dm} \cdot \mathrm{x}$ & $\mathrm{f} 41$ & 0,2869 & $\mathrm{c} 41$ \\
\hline $\mathrm{d} \cdot \mathrm{N} \cdot \mathrm{x}$ & $\mathrm{f} 42$ & 0,1146 & $\mathrm{c} 42$ \\
\hline Dm.N.x & $\mathrm{f} 43$ & $-0,0217$ & $\mathrm{c} 43$ \\
\hline
\end{tabular}

$$
\text { Safety }=f 33 . c 33+f 34 . c 34+\ldots+f 43 . c 43
$$



Fig. 8. Effects of factors on safety of compression spring

From the DOE studies for compression spring, the optimum values of safety and SE are obtained by parameter tuning. As a result, compression spring parameters are listed in Table IX. From these parameters, experimental SE and safety are found as $\mathbf{3 0 . 7} \mathbf{~ m J}$ and $\mathbf{1 . 2 4}$, respectively. In addition to the aim for tuning study mentioned above, manufacturability of the compression spring is also taken 
into consideration, so reasonable values for these parameters are chosen with this conscious.

TABLE X: PARAMETERS OF THE COMPRESSION SPRING

\begin{tabular}{|c|c|c|}
\hline Torsion Spring Constraints & Value & Constraint Type \\
\hline Wire diameter $(\mathrm{d})$ & $0.4 \mathrm{~mm}$ & Geometric \\
\hline Coiling diameter $(\mathrm{Dm})$ & $3.6 \mathrm{~mm}$ & Geometric \\
\hline Coiling Number $(\mathrm{N})$ & 8.5 & Geometric \\
\hline Deflection $(\mathrm{x})$ & $8.6 \mathrm{~mm}$ & Geometric \\
\hline Factor of Safety & 1.24 & Safety \\
\hline
\end{tabular}

\section{CONCLUSION}

In this study, we focused on design of the foldable wing mechanism and optimized the mechanical parameters of the key components on the total deployment time of the missile wings. Firstly, we examined the mechanism and determined the key components, which mostly affect the deployment time of the wing. Then, we analyzed these components on Minitab, which is a Design of Experiment (DOE) tool. By using this method, we achieved the effects of factors (mechanical design parameters) on system SE and safety responses (product quality) as well as the experimental formula of the responses. As a result of the DOE studies, we determined the mechanical design parameters of the components and finalized the design of a novel missile foldable wing mechanism. In future work; we will create the Adams model of the mechanism and complete the dynamic analysis of the mechanism in order to verify the deployment time of the wing. After the dynamic simulation, we will manufacture the mechanism, test the system physically and compare the test results with dynamic simulation results.

\section{ACKNOWLEDGMENT}

The authors would like to thank to ROKETSAN for financial support and encouragement.

\section{REFERENCES}

[1] Y. Ning, W. Nan, Z. Xin, and L. Wei, "Nonlinear flutter wind tunnel test and numerical analysis of folding fins with freeplay nonlinearities," Chinese Journal of Aeronautics, 2016, vol. 29, no. 1, pp. 144-159

[2] B. Acar and A. Yetgin "Design and analysis of a foldable wing mechanism," SIMULIA Community Conference, 2013, Vienna, Austria.
[3] J. D. Jacob and S. W. Smith, "Design limitations of deployable wings for small low altitude UAVS," in Proc. 47th AIAA Aerospace Sciences Meeting Including The New Horizons Forum and Aerospace Exposition 5 - 8 January 2009, Orlando, Florida, AIAA 2009-1291.

[4] A. M. Scott, P. ThomasnAberer, N. R. Japp, and N. C. McGaha, Washington DC, US: United States Patent Office, 2014

[5] K. G. Whitham, United States Patent and Trademark Office 20072012 Strategic Plan, Washington DC, US: United States Patent Office, 2010.

[6] J. E. Shigley, C. R. Mischke, and R. G. Budynes, Mechanical Engineering Design, 7th Edition, p.526

[7] Z. Külünk, S. Çakıroğlu, M. Şahin, and Z. Esen, "Designing spring load system for mechatronic actuator," CPE-POWERENG Conference, 2016, pp.144-159

[8] J. E. Shigley, C. R. Mischke, and R. G. Budynes, Mechanical Engineering Design, 7th edition, pp. 542-549

[9] S. Holzner, Physics 1 for Dummies, 2nd edition, pp. 253-270

[10] J. E. Shigley, C. R. Mischke, R. G. Budynes, Mechanical Engineering Design, 9th Edition, p. 520-533

[11] R. L. Plackett and J. P. Burman, "The design of optimum multifactorial experiments," Biometrika, vol. 34, pp. 255-272, 1946.

[12] H. Esiyok and M. E. Candarli, "Design of experiment approach to the burning rate anomaly of composite solid propellant," AIAA Propulsion and Energy Forum, July 9-11, 2018, Cincinnati, Ohio

[13] R. A. Bettinger, J. T. Black, and J. S. Agte, "Design of experiment approach to atmospheric skip entry maneuver optimization," Journal of Spacecraft and Rockets, vol. 52, no. 3, May-June 2015



Zafer Külünk was born in Duzce, Turkey on 1 April 1988. He received his diploma in mechanical engineering from Middle East Technical University in 2011. After graduation, he joined Ford Motor Company (Istanbul, Turkey) as a design engineer for engine mounting systems (2011). Then, he started to work for Roketsan Missiles Industry (Ankara, Turkey) in 2012 and he is currently working for the same company as a senior mechatronic systems design engineer (design and development of control actuator systems for guided missiles). His current interests are mechanical design, mechatronic systems, guided missile system design and production.

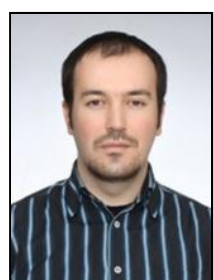

Murat Sahin was born in Kayseri, Turkey on 7 June 1983. He received his B.S. (2005) and M.S. (2008) in electronics engineering from Ankara University, and then he gained his Ph.D. (2015) in electrical technologies from Gazi University. His research focused on linear and non-linear control theory. Murat has been working for design and development of control actuator systems for guided missiles in Roketsan Missile Industry for 12 years, and he is currently chief design engineer in control systems design department. His current interests are intelligent actuator, non-linear control systems and guided missile systems. 